\title{
Histopathological classification and malignant change in gastric polyps
}

\author{
TAKUJI NAKAMURA, GEN-ICHI NAKANO
}

From the First Department of Surgery, Gunma University School of Medicine, 3-39-22, Showa-machi, Maebashi 371, Japan

SUMMARY A total of 611 gastric polyps from 275 cases were studied and were classified into four subtypes. Type I was the most common type and types II, III, and IV were less common. Type I and II, considered to be non-neoplastic polyps because of the absence of dysplasia, showed an extremely low malignant potential. Type III showed a two layer structure, the upper layer of which was composed of dysplastic epithelia. This type showed a low malignant potential despite the dysplasia. The type IV polyp showed macroscopical and histological findings similar to those of colonic adenoma. This type was considered to be truly neoplastic and to be the most important of the four subtypes because of its high malignant potential. Type III and IV should be clearly separated and treated differently.

It has long been generally accepted that gastric polyps have a high potential for malignant change, despite some controversy. ${ }^{2}$ This concept has been adopted by many authors in Japan. ${ }^{3}$ Monaco et al, ${ }^{4}$ however, described the absence of malignant potential in gastric polyps on the basis of a clinical and morphological study of 153 cases. This discrepancy in the estimation of the malignant potential of gastric polyps should be overcome as soon as possible to avoid serious confusion in selection for surgical treatment. Nakamura has considered the discrepancy to arise from the following:

(1) Failure to establish a general definition of gastric polyps and the criteria for malignant change.

(2) The fact that gastric polyps do not represent a uniform lesion from the morphological standpoint and that the various types of gastric polyps could have differing malignant potential. Several classifications of gastric polyps have been proposed, but without universal acceptance..$^{5-8}$ Against this background, Nakamura's previous study was performed on 343 polyps obtained from 116 cases of his own collection during the 16 years from 1949 to 1964. As a result of this study two particular types, other than the common type, were distinguished, each essentially different entities. These two particular types had not been described as established entities in any published work when the articles on gastric polyps were published in Japanese in $1966^{\circ}$ and subsequently in German in $1970 .^{10}$ Gastric

Accepted for publication 28 February 1985 polyps were then classified into three subtypes: type I, type II, and type III.

In 1971, Nakamura described an additional type of gastric polyp, type IV, which had been included in the miscellaneous group in the author's classification because of its low incidence in the previous study. ${ }^{112}$ Since then gastric polyps have been classified into four subtypes.

Recently, gastric polyps collected during the 22 years from 1958 to 1979 have been re-examined histopathologically. This study was performed to throw light on several problems not yet solved about type III and type IV. Problems intended to be clarified in this study are as follows:

(1) Type III polyps have been generally accepted as adenomas ${ }^{13-15}$ because of the dysplastic epithelia, which lines glands in the upper layers of these polyps. Furthermore, type III has been assumed to have high malignant potential, following Nakamura's report on this particular type of gastric polyp in 1962. Recently, however, many authors, including Nakamura, have come to doubt the high malignant potential of this type of polyp.

(2) Several authors have supposed that there is a gradual transformation from the type III to the type IV polyp. As a result they do not recognise type III and type IV as essentially different entities.

(3) Type IV polyps have long been diagnosed as differentiated adenocarcinoma by several workers in Japan. Polyps with focal cancer were often assumed not to be benign adenomas with focal carcinoma, but adenocarcinomas in toto. 
Although Nakamura's description of gastric polyps has been quoted in papers and monographs by several writers, ${ }^{13}{ }^{16}$ not only in Japan but also in other countries, sufficient understanding has not yet been achieved, especially in English speaking countries. The intention of this paper is to describe the histological findings of the four subtypes and discuss their malignant potential in order to clarify this position.

\section{Material and methods}

A total of 611 gastric polyps from 275 patients were examined histopathologically. Material was obtained at operation in 165 cases, by polypectomy in 41 cases, and at necropsy in 69 cases at the Tokyo Geriatric Hospital and Gunma University Hospital from 1953 to 1979 (Table 1). Gastric polyps or polyposis combined with adenomatosis coli, PeutzJeghers syndrome, and Cronkhite-Canada syndrome were not included in this series.

Nakamura's definition of gastric polyps is as follows:

(1) Circumscribed protruding lesions of the gastric mucous membrane.

(2) Clearly demarcated lesions despite varying shape.

(3) Benign lesions, including cases of malignant change.

Submucosal lesions such as aberrant pancreas were excluded. Sections were cut from the centre of the polyp including some adjacent mucous membrane. A greater number of sections were taken in larger polyps and serial sections also were made in required cases. They were fixed in $10 \%$ formalin and embedded in paraffin wax. All sections were stained with haematoxylin and eosin and the periodic acid Schiff stain to confirm the presence of mucus.

\section{Results}

HISTOPATHOLOGICAL CLASSIFICATION

All the 611 polyps from 275 cases were classified histopathologically into the following four subtypes: type I, type II, type III, and type IV. Type I was the most common type. Type II, type III, and type IV were less common, but they required careful consideration from the point of view of treatment.

\section{Type 1}

Sixty to eighty per cent of all gastric polyps were type I. Most of the type I polyps were pedunculated and solitary. Their most common site was the pyloric antrum. They were composed mainly of hyperplastic gland ducts similar to gastric foveolae. Pyloric glands were also recognised but usually in small numbers. Hyperplastic gland ducts were lined with high columnar epithelial cells. Their cytoplasm was clear and their spindle shaped nuclei were situated at the botton of the cells. Although the gland ducts were irregularly proliferated with branching, winding, and dilatation to form cysts, no cellular dysplasia was recognised in these epithelial cells. The muscularis mucosae ascending through the stalk of the polyp made a core and then divided itself into many thin branches within the polyp. The interstitium of the polyp was usually oedematous, poor in cells, and congested (Fig. 1). Cancer focus (Fig. 2) was seen in the superficial area of the inset of Fig. 1.

\section{Type II}

Polyps of this type were usually multiple and distributed in the distal fundic mucosa of the stomach and they were not found in the pyloric antrum (Fig. 3). Most of them had pinkish dimples at their tips. Histologically, the central portion of the polyp corresponding to the dimple usually had a superficial erosion and was composed of hyperplastic regenerative epithelium (Fig. 4). In this part, darkly staining gland ducts showed a gradual transition to more clearly stained gland ducts at the bottom, similar to the pyloric glands. These gland ducts often showed a core similar to onion skin sharply demarcated from the surrounding part (Fig. 5). Interestingly, neither chief cells nor parietal cells were seen in the lining of the gland ducts in the central portion of the polyp. In the peripheral part of the polyp, irregular hyperplastic gastric foveolae were connected to the fundic glands containing parietal or chief cells, or both. From these findings it was assumed that the type II polyp was derived from an excessive and persistent healing process of a pre-excising erosion in the cen-

Table 1 Material included in the study (275 patients, 611 polyps)*

\begin{tabular}{|c|c|c|c|c|c|c|}
\hline & \multicolumn{2}{|c|}{ Tokyo Geriatric Hospital } & \multicolumn{2}{|c|}{ Gunma University Hospital } & \multicolumn{2}{|l|}{ Total } \\
\hline & No of cases & No of polyps & No of cases & No of polyps & No of cases & No of polyps \\
\hline $\begin{array}{l}\text { Operation } \\
\text { Polypectomy } \\
\text { Necropsy } \\
\text { Total }\end{array}$ & $\begin{array}{r}71 \\
0 \\
69 \\
140\end{array}$ & $\begin{array}{r}197 \\
0 \\
146 \\
343\end{array}$ & $\begin{array}{r}94 \\
41 \\
0 \\
135\end{array}$ & $\begin{array}{r}214 \\
54 \\
0 \\
268\end{array}$ & $\begin{array}{r}165 \\
41 \\
69 \\
275\end{array}$ & $\begin{array}{r}411 \\
54 \\
146 \\
611\end{array}$ \\
\hline
\end{tabular}

*Patients admitted to Tokyo Geriatric Hospital (1958-69) and Gunma University Hospital (1953-79). 


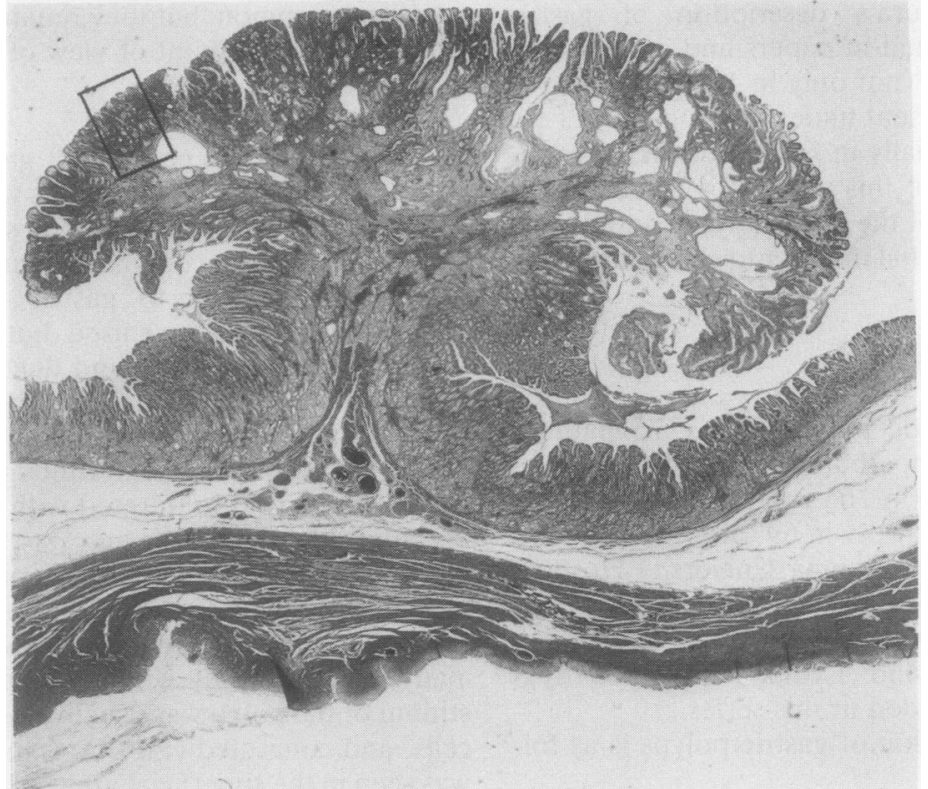

Fig. 1 Cross section of type I polyp. The greater part of this polyp is composed of irregularly proliferated non-dysplastic glands and cysts. Haematoxylin and eosin. $\times 6$.

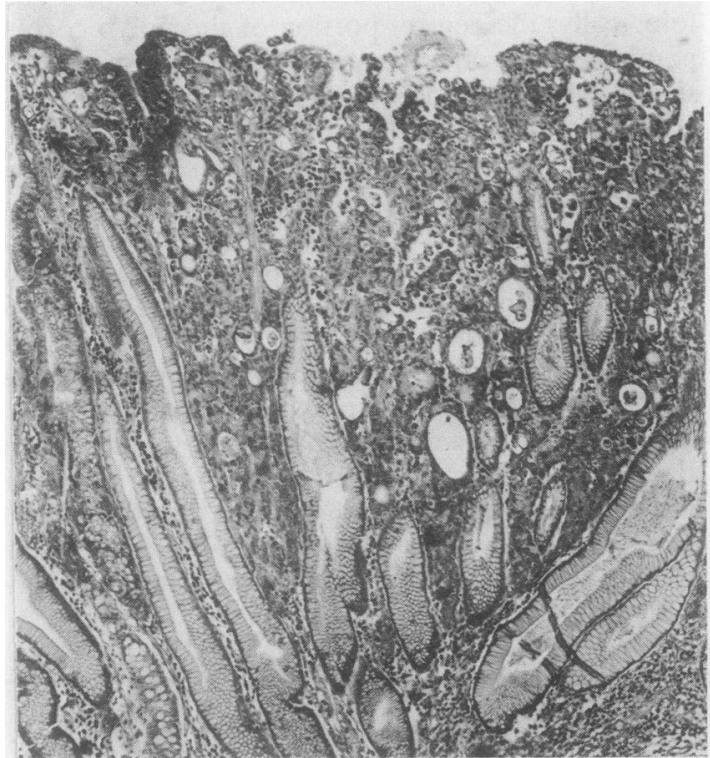

Fig. 2 Cancer focus of type I polyp. (Magnified view of a part of superficial area in the inset of Fig. 1). A poorly differentiated adenocarcinoma infiltrated in the interstitial space can be seen. Haematoxylin and eosin. Original magnification $\times 64$.

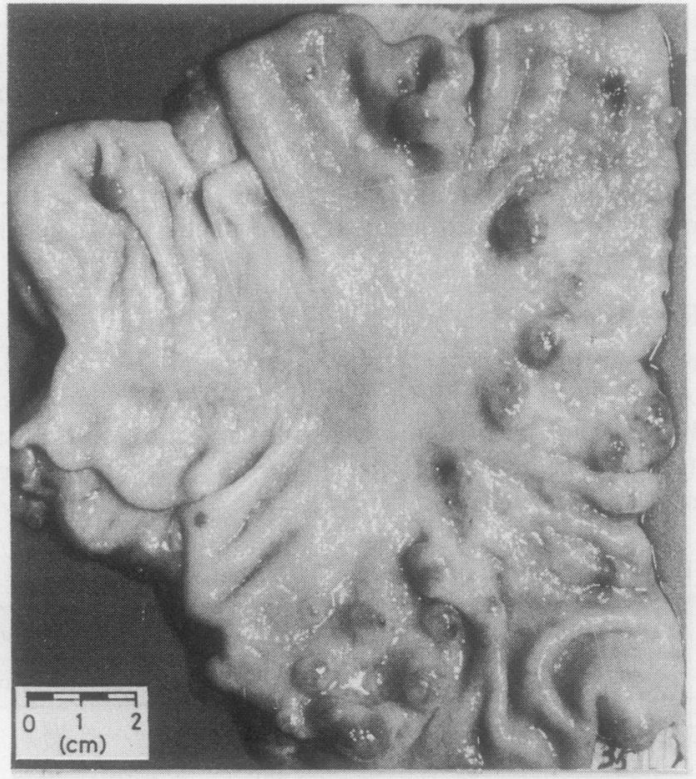

Fig. 3 Polyps of type II are distributed in the distal fundic mucosa of the stomach. 


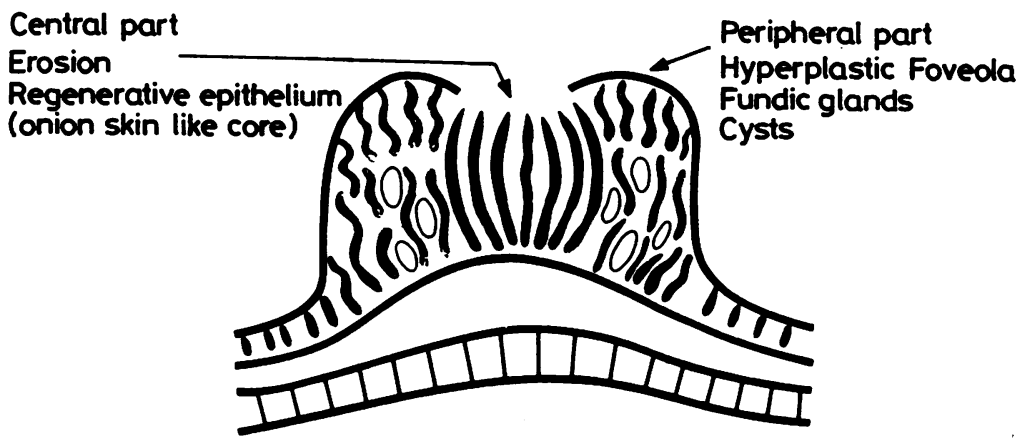

Fig. 4 Structure of type II polyp. Central part of the polyp is composed of erosion with a core like onion skin; the peripheral part is composed of hyperplastic foveolae and cysts.

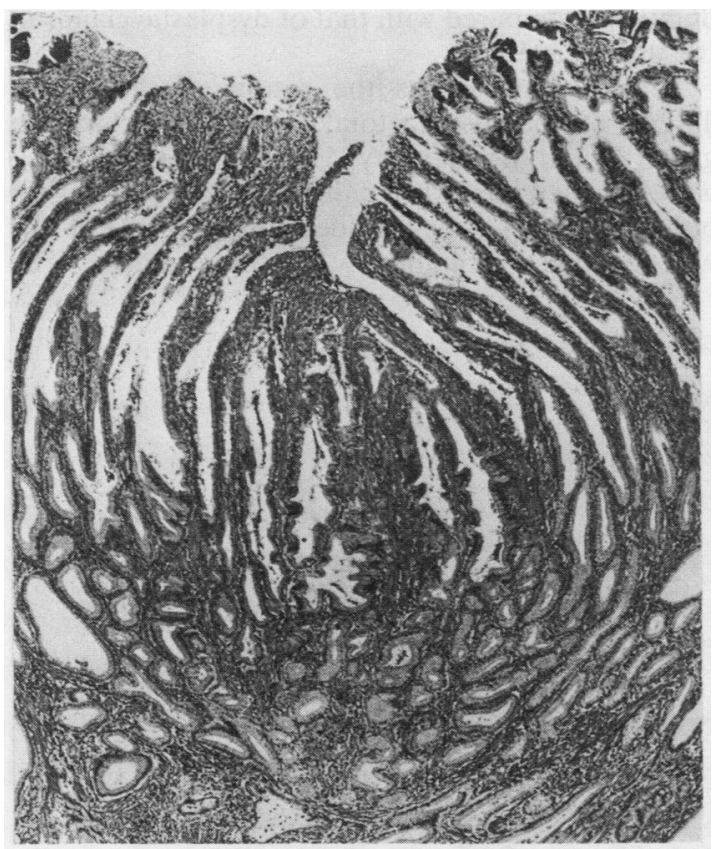

Fig. 5 Gland ducts in central portion of type II polyp show a core like onion skin sharply demarcated from the surrounding gland ducts. Haematoxylin and eosin. Original magnification $\times 40$.

tral portion of the polyp. Muscularis mucosae was often split or fibrously thickened at the base of the polyp of this type. The central and surrounding peripheral portion were clearly demarcated, especially in the small polyps, and hyperplasia of lymphoid tissue occasionally intervened between these two portions. Such findings of muscularis mucosae and hyperplasia of lymphoid tissue were considered to support the above mentioned histogenesis of the type II polyp.

\section{Type III}

Polyps of this type were usually sessile with an uneven surface, resembling flower beds or mountain ranges (Figs. 6-8). Most of them were similar to gastric mucosa in colour, solitary, and were distributed in the pyloric antrum. Histologically, these polyps showed a characteristic two layer structure. The upper layer of the polyp was composed of densely arranged vertical glands showing mild dysplasia, which were similar to Lieberkühn's glands. These gland ducts were lined by coiumnar cells, which were extremely darkly stained not only in the cytoplasm but also in the nuclei. These nuclei were elongated and spindle shaped with an irregular contour. Fine nuclear structure was not recognised because of the extreme hyperchromatism. Various grades of stratification were also seen in most nuclei but were not as pronounced as those seen in carcinoma (Fig. 7). Some goblet cells were recognised in their upper part and some Paneth's cells in their lower parts. Brush borders were also seen in these gland ducts but not consistently. These dysplastic epithelial cells were therefore assumed to have a close relation to intestinal epithelium. The lower layer of the polyp comprised hyperplastic pyloric glands, gland ducts lined by metaplastic intestinal epithelium, and multiple cysts which showed no dysplasia (Figs. 7-9).

As mentioned above, the two layer structure is one of the characteristics of type III polyps. The upper layer comprises dysplastic glands and the lower layer non-dysplastic glands, including pyloric glands, gland ducts lined by metaplastic intestinal epithelium, and cysts. The relation between the size of polyp and the degree of proliferation of non- 


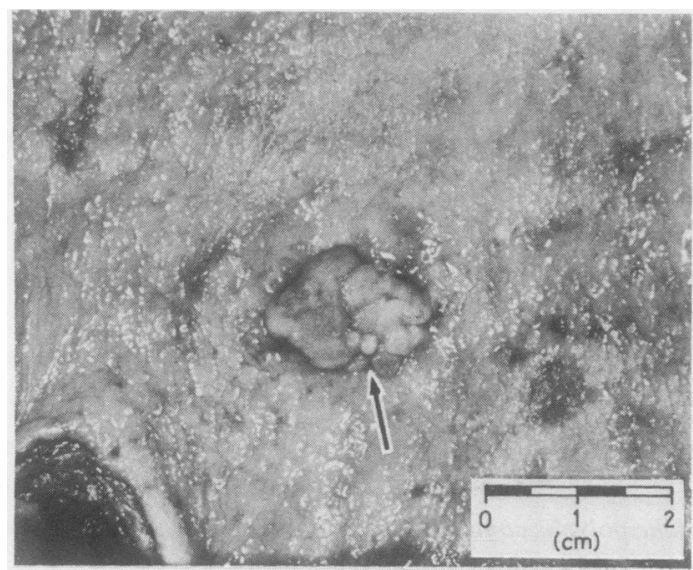

Fig. 6 Type III polyp located at the antrum (arrow) is sessile and shows an uneven surface resembling flower beds or mountain ranges.

dysplastic glands in the lower layer was studied in type III polyps. Sixty eight type III polyps from 49 cases were examined histopathologically. The features of the central part could be seen microscopically in 65 polyps and there were three polyps that were not suitable for examination. The size of polyp was measured by the greater diameter. The $65 \stackrel{2}{\circ}$ polyps were divided into the following three groups. according to the degree of proliferation of nondysplastic glands in the lower layer.

Group 1-the two layer structure was not so dis-? tinct and the greater part of the polyp was occupied by dysplastic glands, but non-dysplastic glands were also seen at the base even though these were few in number.

Group 2-the two layer structure was clearly seen $\vec{\circ}$ and the proliferation in the lower layer was pro- $\overrightarrow{-}$ nounced. Compared with the proliferation of dys- $\vec{\omega}$ plastic glands in the upper layer, that of non- dysplastic glands in the lower layer was about the? same or a little less.

Group 3-the two layer structure was clearly seen. and the proliferation of non-dysplastic glands in the lower layer was very pronounced and was pre-응 dominant compared with that of dysplastic glands in. the upper layer.

Table 2 summarises the results of this study Twenty one polyps, of a total of 65 , were included in $\overrightarrow{0}$ group 1 , and the majority, 15 of 21 polyps $(71 \%), \infty$ were smaller than $1 \mathrm{~cm}$ in diameter. Thirty six polyps $(55.4 \%)$ were included in group 2 , and thiso was the most common of the three groups. The

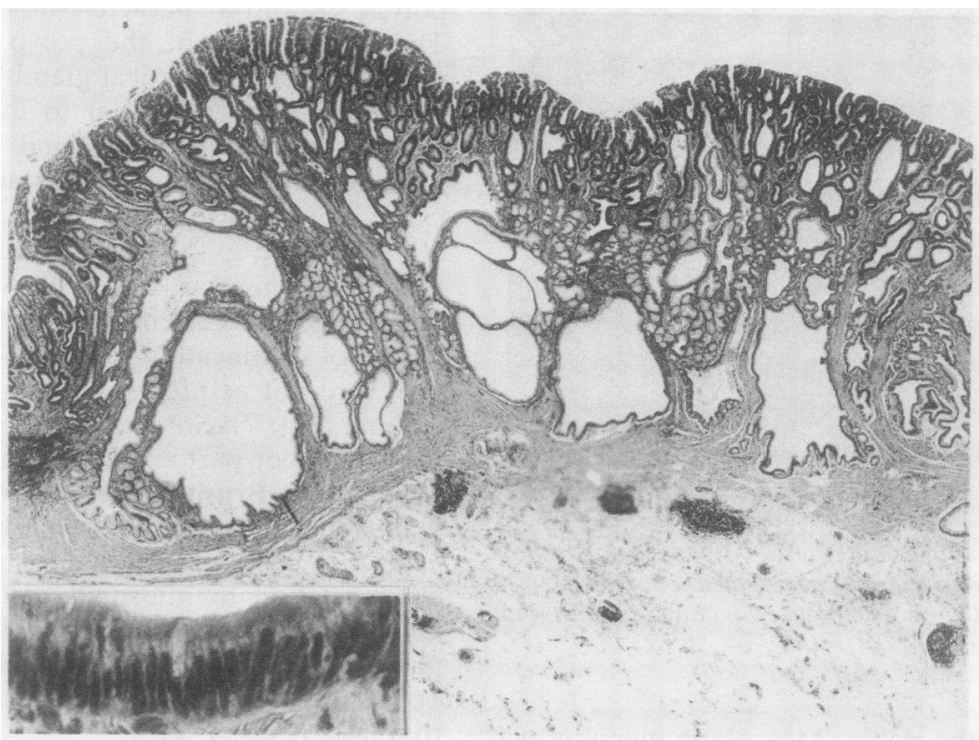

Fig. 7 Histology of type 111 polyp. The two layer structure is clearly recognised and the proliferation in the lower layer is pronounced. Compared with the proliferation of dysplastic glands in the upper layer, that of non-dysplastic glands in the lower layer is about the same or a little less. Haematoxylin and eosin. $\times 15$. Inset shows high power view $(\times 400)$ of dysplastic glands in the upper layer. The cells are lined by dysplastic columnar cells, which are extremely darkly stained not only in the cytoplasm but also in the nuclei. 


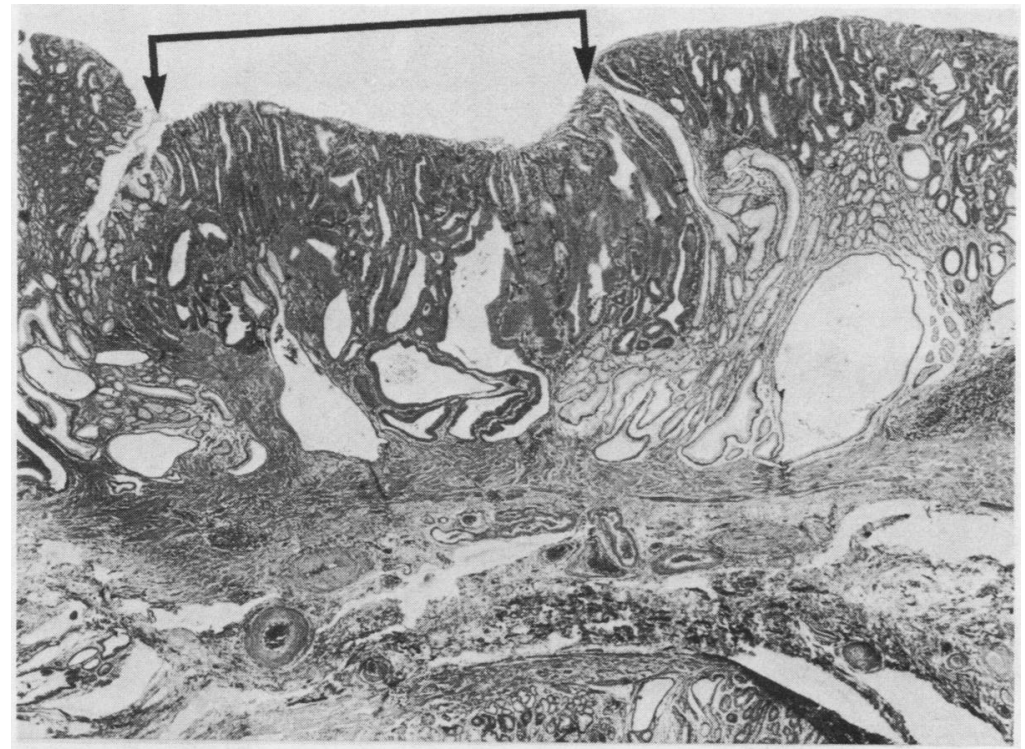

Fig. 8 Cancer focus of type III polyp. Definite cancerous dysplastic glands are seen in the depressed part of this picture (arrows). Haematoxylin and eosin. $\times 16$.

Histology of type III polyp two layer structure

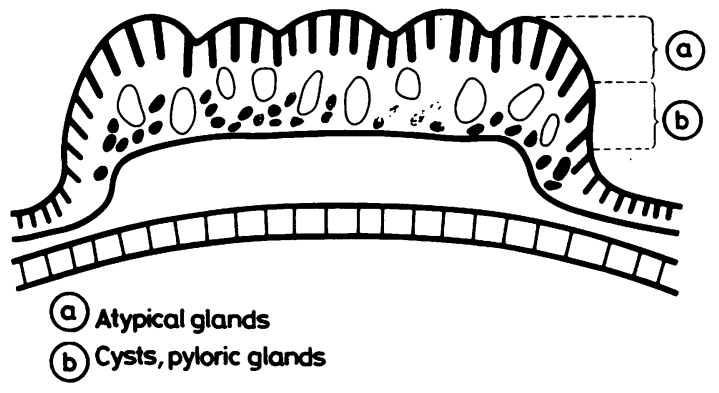

Fig. 9 Schema of type III polyp shows a characteristic two layer structure. Upper layer is composed of densely arranged vertical dysplastic glands: and lower layer is composed of hyperplastic pyloric glands and multiple cysts.

diameters of polyps in this group were about the same, ranging between $0.5 \mathrm{~cm}$ and more than $2.0 \mathrm{~cm}$ and only one was below $0.5 \mathrm{~cm}$. Fifteen polyps measured between $0.5 \mathrm{~cm}$ and $1.0 \mathrm{~cm}$. These were assumed to be the most usual in size and typical in their histology among type III polyps. In group 3, a total of eight polyps were larger than $1.0 \mathrm{~cm}$, and five of the eight $(62.5 \%)$ were larger than $2.0 \mathrm{~cm}$. There were no polyps with a diameter smaller than $1.0 \mathrm{~cm}$.

The tendency for the size of polyp to be directly related to the proliferation in the lower layer has been noticed previously by Nakamura. The results of this study establish this tendency more firmly.

\section{Type IV}

Type IV polyps were macroscopically similar to adenomas of the colon. They were either sessile or pedunculated and their surfaces were finely lobulated with intercommunicating clefts. They showed mild, moderate, or severe dysplasia in the cytological and architectural aspects and were composed of columnar epithelium. These columnar cells are darkly stained not only in the cytoplasm but also in the nuclei. Such hyperchromatism was not, however,

Table 2 Proliferation of non-dysplastic glands in the lower layer of type III polyps: relation to the size of polyps (65 polyps in 49 cases)

\begin{tabular}{llccccc}
\hline Grade of proliferation & \multicolumn{2}{l}{ No of polyps in each size } & & \multicolumn{2}{c}{ Total (\%) } \\
\cline { 2 - 6 } & $\leqslant 0 \cdot 5$ & $0 \cdot 6-1 \cdot 0$ & $1 \cdot 1-1 \cdot 5$ & $1 \cdot 6-2 \cdot 0$ & $2 \cdot 0<(\mathrm{cm})$ \\
\hline Group I & 8 & 7 & 3 & 3 & 0 & $21(32 \cdot 3)$ \\
Group II & 1 & 15 & 6 & 6 & 8 & $36(55 \cdot 4)$ \\
Group III & 0 & 0 & 2 & 1 & 5 & $8(12 \cdot 3)$ \\
Total & 9 & 22 & 11 & 10 & 13 & $65(100)$ \\
\hline
\end{tabular}




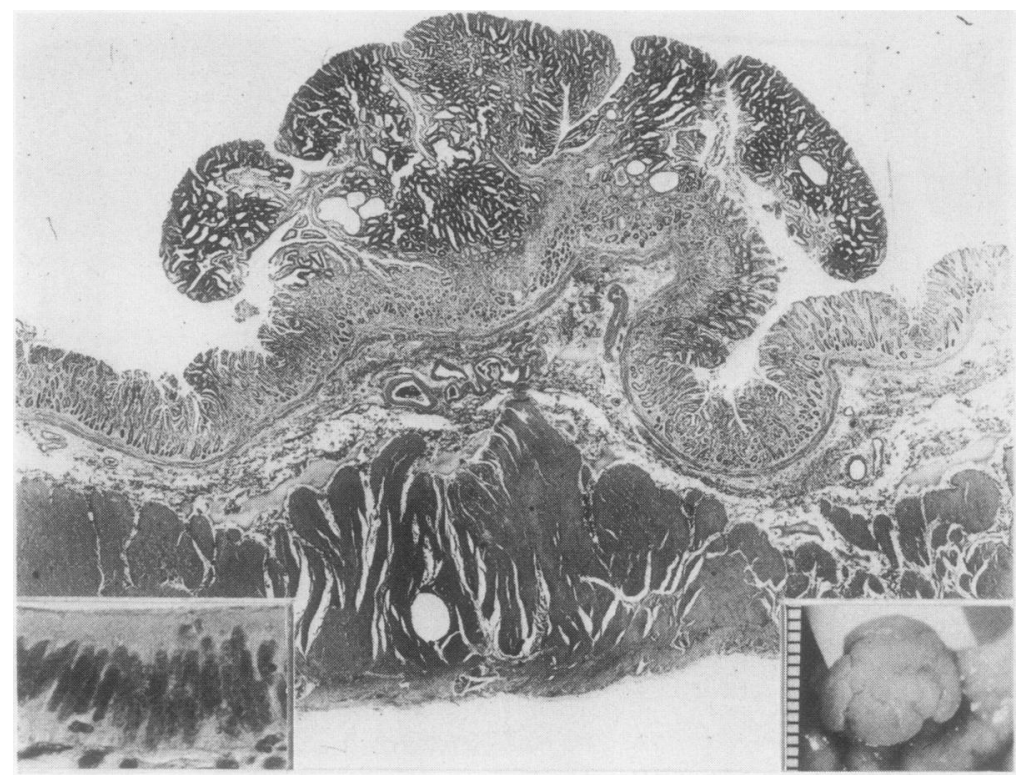

Fig. 10 Tubular adenoma of type IV polyp, composed of abnormal glands lined with darkly stained dysplastic columnar epithelium. Haematoxylin and eosin. $\times 7$. Right inset shows the polyp, which is pedunculated and superficially uneven. Left inset shows abnormal glands, which are darkly stained not only in the cytoplasm but also in the nuclei. Such hyperchromatism, however, is not as pronounced as that seen in type III polyps. Nuclei are mostly elongated, oval-shaped, and show regular contours. Haematoxylin and eosin. Original magnification $\times 400$.

as pronounced as that seen in the type III polyp. Nuclei of type IV polyps were mostly elongated, oval shaped, and showed a regular contour. Fine nuclear structure was well recognised because hyperchromatism of these nuclei was not as pronounced as that seen in the type III polyp. Nucleoli were often prominent in type IV. Various grades of stratification were also observed in most nuclei, but not to the extent seen in carcinoma. Many of the dysplastic glands showed features of intestinal metaplasia (Figs. 10 and 11).

The histological structure comprised a tubular pattern (Fig. 10) in 27 polyps, tubulo-villous (Fig. 12) in nine polyps, and villous (Fig. 14) in three polyps. A similar distribution of these histological types is seen in the adenoma of the colon. Several focal cancers were found in type IV polyps but neither lymph node metastasis nor submucosal invasion was seen in any case. Judging from the criteria, which were considered most appropriate to diagnose the malignancy, a total of 39 polyps in this group were considered not to be adenocarcinomas but to be benign lesions, even in those cases with focal cancer.

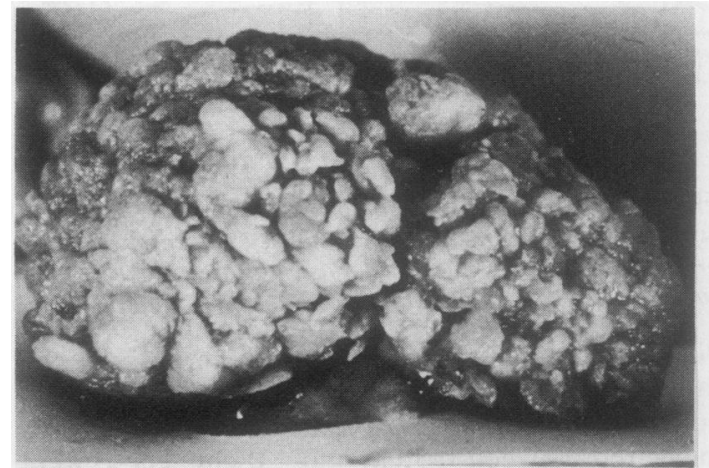

Fig. 11 Tubulo-villous adenoma of type IV polyp, which is pedunculated, located at the fundus. The surface is finely lobulated by intercommunicating clefts, measuring $5.0 \times$ $3.5 \times 3.0 \mathrm{~cm}$.

MALIGNANT CHANGE

The criteria for malignant change were as follows:

(1) Both malignant and benign tissues should $\bar{Q}$ coexist in one polyp.

(2) The benign sector should be large enough to 


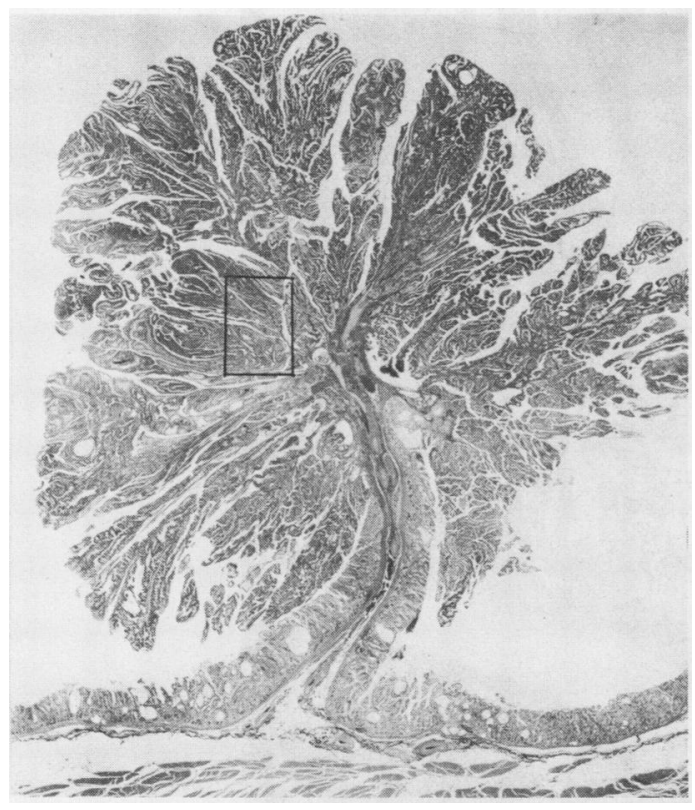

Fig. 12 Histology of Fig. 11 shows tubulo-villous adenoma. Haematoxylin and eosin. Original magnification $\times 3 \cdot 5$.

prove the precursor is a benign polyp.

(3) Malignancy could be established not only where interstitial or submucosal invasion was discerned, but also when cellular and structural atypia were sufficiently severe without such invasion.

In type I, malignant change was not common and focal cancers were found in only two polyps of 335 examined $(0.6 \%)$. Figs. 1 and 2 show the microscopical findings in one of these cases. This polyp was pedunculated, measuring 1.6 by $1.4 \mathrm{~cm}$, and was situated in the pyloric antrum. One third of the superficial area of the polyp was composed of highly dysplastic epithelial cells (Fig. 2). Although stalk invasion was not seen, this lesion would be expected to have acquired an invasive character in the near future because of the highly dysplastic nature of the tumour cells.

In type II no malignant change had occurred in 36 cases, which was compatible with the author's criteria.
In type III focal cancers were seen in four of 68 polyps examined $(5 \cdot 9 \%)$. The malignant potential was low but far higher than those of type I and II. ${ }^{17} 18$ Fig. 8 shows a microscopical view of one of the most typical cases with malignant change.

In type IV focal cancers were seen in 13 of 39 polyps (33.3\%). Type IV showed the highest potential for malignant change among the four subtypes.

Although type III and type IV were both composed of dysplastic epithelia and have been included together as adenomas, considerable disparity was recognised between their malignant potential (Table 3).

Fig. 11 shows a typical case of malignant change in type IV. This polyp, located on the anterior wall of the fundus, was pedunculated, papillary on its surface, measured 5.0 by $3.5 \mathrm{~cm}$, and was histologically a tubulo-villous adenoma (Fig. 12). A small cancer focus was seen at the centre of the polyp (Fig. 13). The histological features of benign tubular adenoma were seen in the right half of Fig. 14 and adenocarcinoma was observed in the left half. These histologically quite different parts showed a close contact and a sharp border.

\section{Discussion}

Borrmann ${ }^{14}$ and Konjetzny ${ }^{10}$ provided early descriptions of different types of gastric polyp. Subsequently, Merkel, ${ }^{6}$ Reifferscheid ${ }^{8}$ and Gieseler ${ }^{5}$ classified gastric polyps on the basis proposed by Borrmann and Konjetzny. In 1951 Walk reported two cases and analysed villous tumours or cauliflower like papilloma of the stomach. ${ }^{21} \mathrm{He}$ collated 51 published cases of polyps with significant malignant potential, indicating that these should be distinguished from common gastric polyp. In Monaco's series three sessile polyps similar to the adenoma of the colon and 10 polyps composed of highly dysplastic epithelium were included in the total of 153 gastric polyps. ${ }^{4}$ Ming classified gastric polyps into two types: regenerative polyps and adenomatous polyps. The regenerative type had no malignant potential but the adenomatous type were neoplastic and showed high malignant potential. His histological classification of gastric polyps has been generally accepted not only in Japan but also in

Table 3 Focal cancers in gastric polyps in each subtype (275 patients, 611 polyps)*

\begin{tabular}{llll}
\hline Subtypes & Cases & No of polyps & No with focal cancers (\%) \\
\hline Type I & 194 & 335 & $2(0 \cdot 6)$ \\
Type II & 36 & 169 & $0(0)$ \\
Type III & 51 & 68 & $4(5 \cdot 9)$ \\
Type IV & 36 & 39 & $13(33 \cdot 3)$ \\
\hline
\end{tabular}

*Patients admitted to Tokyo Geriatric Hospital (1958-69) and Gunma University Hospital (1953-79). 


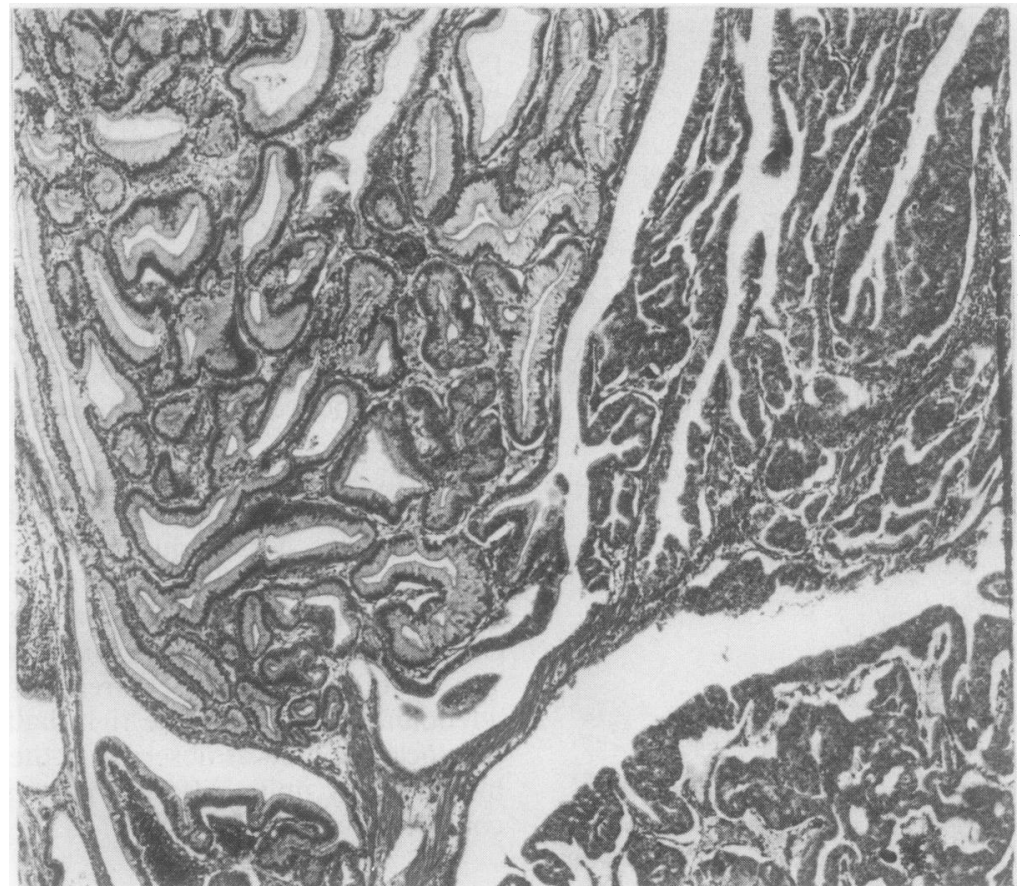

Fig. 13 Magnified view of inset in Fig. 12 showing cancer focus. Tubular adenoma (left) and tubular adenocarcinoma (right). Haematoxylin and eosin. Original magnification $\times 40$.

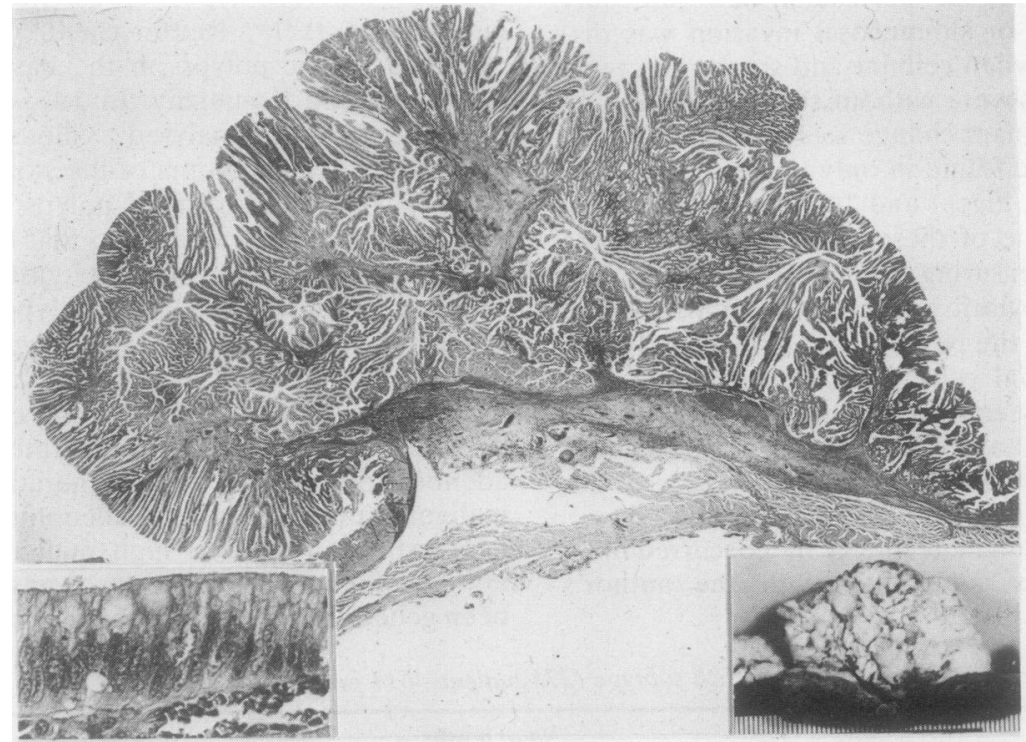

Fig. 14 Microscopical view of villous adenoma. Haematoxylin and eosin. Original magnification $\times 2.7$. Right inset shows macroscopical view of this polyp, which is sessile, located at the gastric antrum, and measures $5.2 \times 4.5 \times 3.5 \mathrm{~cm}$. Left inset shows dysplastic cells with elongated oval shaped nuclei. Haematoxylin and eosin. Original magnification $\times 400$. The fine nuclear structure is clearly seen because hyperchromatism of these nuclei is not as pronounced as that seen in type III polyps. (Fig. 7) Nucleoli are also prominent in type IV polyps. 
Europe and the United States. These studies show that gastric polyps are not homogeneous but consist of essentially different subtypes.

In this study 611 gastric polyps from 275 cases were studied histopathologically. Nakamura's definition of gastric polyps and the criteria for malignant change were presented to avoid the discrepancy mentioned in the introduction. Gastric polyps were divided into subtypes as follows: the common type (type I) and three other types (types II, III, and IV). They were essentially different entities, showing no mutual transformation. Of these four subtypes, type I and II were considered to be nonneoplastic polyps because no dysplasia was seen in their epithelium. Hyperplastic polyp might be a preferable term for these subtypes. Type I polyp is the common type, representing most gastric polyps and showing no dysplasia and an extremely low malignant potential. From the histological findings it was considered that this type corresponded to lesions previously described as fibroadenoma, ${ }^{19}$ adenomatous polyp,,$^{22}$ and regenerative polyps. ${ }^{7}$

Type II polyps were usually multiple, generated in the fundic gland region, and showed particular histological features. These polyps had not been described as a specific subtype before Nakamura's classification. Several authors ${ }^{192324}$ have shown macroscopical pictures of cases with multiple polyps similar to this type, but their histological characteristics were not defined.

Konjetzny ${ }^{20}$ reported sessile and flower bed like polypoid lesions of the stomach, which were composed of highly dysplastic glands. A histological picture of this lesion presented in his paper was similar to that of type III polyp. Matsumoto ${ }^{25}$ described flat polypoid lesions in stomachs at necropsy and pointed out their malignant potential. These lesions are considered to correspond to type III polyp.

Type III is regarded as a benign adenoma showing a two layer structure: dysplastic glands in the upper layer and non-dysplastic glands in the lower layer. These components showed concomitant growth, but the larger the polyp, the more dominant was the proliferation of the lower non-dysplastic layer. This finding was interesting and in contrast to the structure of adenoma of the colon. In addition, the malignant potential of type III was far lower than that of type IV.
Several Japanese authors as well as Ming have supposed that there is a gradual transformation from the type III to the type IV polyp. ${ }^{26-29}$ Ming states: "When the lesion is early and small, it is seen as a flat adenoma, classified as a Type III polyp by Nakamura, manifesting a primarily horizontal growth. When vertical growth is pronounced, papillary or villous patterns become evident and the tumor may become pedunculated. Adenomas may therefore be divided into two major types: the flat type and the papillary or villous type. The primary importance of the division is chronological." This study, however, shows that there is no transformation from type III to type IV, because of the finding that the larger the type III polyp, the more dominant was the proliferation in the non-dysplastic lower layer.

Type IV was regarded as a benign neoplasm, corresponding to the lesions reported as villous tumours by Walk, ${ }^{21}$ as adenomatous polyp by Ming, ${ }^{7}$ and as villous and tubulovillous adenoma by Oota. ${ }^{30}$ This type was the most important polyp of the four subtypes because of its high malignant potential, also described by Walk and Ming.

In conclusion it must be emphasised that types III and IV polyps are essentially different entities because they show not only different histological features, but also differing malignant potentials (Table 4). Although the type III polyp and the type IV tubular adenoma are both tubular adenomas, they are none the less quite distinct. Tubular adenoma type IV is similar to that found in the colon, not only macroscopically, but also microscopically and is composed of tortuous or branching tubules showing moderate dysplasia. On the other hand, adenoma type III is composed of straight perpendicular tubules imitating Lieberkühn's glands and showing only mild dysplasia. Another peculiar characteristic of type III is the two layer structure. Although these two subtypes have often been included together as a borderline lesion, ${ }^{142627}$ they should be clearly separated and treated differently.

We are indebted to $\mathrm{Dr} M$ Yamashiro, Dr $K$ Shimada, and all members of Tokyo Geriatric Hospital, who helped greatly in the preparation of this work, and als̀o to Dr BC Morson, St Mark's Hospital for his advice and encouragement.

Table 4 Comparison of morphology in type III and type IV polyps

\begin{tabular}{|c|c|c|}
\hline & Type III & Type IV \\
\hline $\begin{array}{l}\text { Macroscopical appearance } \\
\text { Microscopical appearance } \\
\text { Dysplasia } \\
\text { Malignant potential }\end{array}$ & $\begin{array}{l}\text { Sessile adenoma found particularly in the stomach } \\
\text { Tubular in two layer structure } \\
\text { Mild } \\
\text { Low }\end{array}$ & $\begin{array}{l}\text { Similar to adenomas of the colon } \\
\text { Tubular, tubulovillous, villous } \\
\text { Moderate, severe } \\
\text { High }\end{array}$ \\
\hline
\end{tabular}


This work was supported by Grant-in-aid for Cancer Research from the Ministry of Health and Welfare (57-2) and the Ministry of Education, Science and Culture of Japan (001073), (59010091).

\section{References}

' Paul WD. Logan EP. Polyps of the stomach with reference to the gastroscopic findings. Gastroenterology 1974;8:592-606.

${ }^{2}$ Carey JB, Hay L. Gastric polyps. Gastroenterology 1948; 10: 102-7.

${ }^{3}$ Kuru M. Premalignant condition (In Japanese). Journal of the Japanese Surgical Society 1952;53:537-83.

${ }^{4}$ Monaco AP, Roth SI, Castleman B, et al. Adenomatous polyp of the stomach. A clinical and pathological study of 153 cases. Cancer 1962;15:456-66.

s Gieseler H. Zur Klinik u Pathologie der Magenpolypen. Langenbecks. Arch Klin Chir 1962;299:637-53.

- Merkel H. Geschwülste des Magens. In: Kaufmann ed. Spezielle Pathologische Anatomie 1955:1019-48.

7 Ming S. Goleman H. Gastric polyps. A histological classification and its relation to carcinoma. Cancer 1965;18:721-6.

${ }^{8}$ Reifferscheid M. Die gutartigen Tumoren des Magens und Duodenumes. Med Klin 1959;54:41-6.

" Nakamura T, Iwamaru M. Takegawa K, et al. Particular types of the gastric polyps (In Japanese). Japanese Journal of Clinical Medicine 1966;24:1156-64.

${ }^{10}$ Nakamura T. Pathohistologische Einteilung der Magenpolypen mit spezifischer Betrachtung ihrer maligne Entartung. Der Chirurg 1970;41:122-130.

"Nakamura T. Gastric polyp similar to adenoma of the large intestine (In Japanese). Japanese Journal of Gastroenterology 1971;68:1043-4.

${ }_{12}$ Nakamura T. Polyp and early cancer of the stomach (In Japanese). Proceedings of the 18th general assembly of the Japan Medical Congress, Tokyo: The Japanese association of Medical Sciences 1971:1014-8.

${ }^{13}$ Morson BC, Dawson IMP. Benign epithelial tumors and polyps. In: Jones FA. ed. Gastrointestinal pathology. 2nd ed. London: Blackwell Scientific Publications, 1979:140-7.

${ }^{4}$ Sugano H, Nakamura K. Takagi K. An atypical epithelium of the stomach. A clinicopathological entity. GANN Monograph on Cancer Research 1979;11:257-69.

is Watanabe H. Argentaffin cells in adenoma of the stomach. Cancer 1972;30:1267-72.

${ }^{16}$ Elster K. Histologic classification of gastric polyps. In: Morson BC, ed. Pathology of the gastrointestinal tract, Berlin: Springer-Verlag 1976:77-94.

${ }^{17}$ Nakamura T. Histopathological study of flat polypoid lesions including type III gastric polyp (In Japanese). Japanese Journal of Gastroenterology 1967;64:790-3.

i* Nakamura T. Malignant change of gastric polyps. with special reference to histopathological classification (In Japanese). Stomach and Intestine 1968:3:737-47.

"Borrmann R. Geschwülste des Magens. Henke-Lubarsch, Handbuch $d$ spez pathol Anatomie u Histologie, Bd4. Berlin, 1926:812-1052.

${ }^{20}$ Konjetzny GE. Die Entzündung des Magens, Henke-Lubarsch. Handbuch d spez pathol Anatomie u Histologie Bd4. Berlin. 1928:768-933.

${ }^{21}$ Walk L. Villous tumor of the stomach. Arch Intern Med 1951:87:560-9.

${ }^{22}$ Stout AP. Lattes R. Tumors of the stomach. In: Firminger HI. ed. Atlas of tumor pathology, Section VI. Fascicle 21. Washington DC: Armed Forces Institute of Pathology 1953:21-50.

${ }^{23}$ Konjetzny GE. Gibt es eine Anzeige zur chirurgischen Behandlung der Gastitis? Arch Klin Chir 1928;151:370-405.

${ }_{24}^{24}$ Valdes-Dapena AM. Stein GN. Gastric polyposis. In: Morphologic pathology of the alimentary canal. Philadelphia: WB Saunders, 1970:230-1.

${ }^{24}$ Matsumoto M. Premalignant condition of the digestive system (In Japanese). Japanese Journal of Geriatrics 1962;6: 158-64.

${ }^{26}$ Hirota T. The histology of borderline lesions of the stomach (In Japanese). Saishin-lgaku 1981;36:41-7.

${ }^{27}$ Kato Y. Yanagisawa A. Sugano H. Borderline lesions (ATP) of the stomach (In Japanese). Saishin-Igaku 1981;36:21-30.

${ }^{2 *}$ Taniguchi H, Ishigura S, Mishima T. Histopathological and histochemical studies on the borderline lesion of the stomach (In Japanese). Saishin-Igaku 1981:36:31-40.

${ }^{24}$ Ming S. The classification and significance of gastric polyps. In: Yardley $\mathrm{JH}$, ed. International academy of pathology monograph. The gastrointestinal tract. Baltimore: The Williams \& Wilkins Company, 1977:149-75.

${ }^{30}$ Oota K. Sobin LH. Gastric tumors, Histological typing of gastric and oesophageal tumours, Geneva: World Health Organisation. 1977:37.

Requests for reprints to: Professor Takuli Nakamura, Department of Surgery, Gunma University School of Medicine, 3-39-22, Showa-Machi Maebashi 371, Japan. 